\title{
Biological responses in marine no-take reserves versus partially protected areas
}

\author{
Sarah E. Lester ${ }^{1,3, *}$, Benjamin S. Halpern $^{2}$ \\ ${ }^{1}$ Institute of Marine Sciences, Long Marine Laboratory, 100 Shaffer Road, University of California, Santa Cruz, \\ California 95060, USA \\ ${ }^{2}$ National Center for Ecological Analysis and Synthesis, 735 State Street, Suite 300, University of California, Santa Barbara, \\ California 93101, USA \\ ${ }^{3}$ Present address: Marine Science Institute, University of California, Santa Barbara, California 93106, USA
}

\begin{abstract}
Marine Protected Areas (MPAs) are a common tool for conserving and managing marine and coastal ecosystems. MPAs encompass a range of protection levels, from fully protected no-take reserves to restriction of only particular activities, gear types, user groups, target species, or extraction periods. There is a growing body of scientific evidence supporting the ecological benefits of full reserve protection, but it is more difficult to generalize about the effects of other types of MPAs, in part because they include a range of actual protection levels. However, it is critical to determine whether partial protection and no-take reserves provide similar ecological benefits given potential economic costs of lost fishing grounds in no-take areas, common sociopolitical opposition to full protection, and promotion of partially protected areas as a compromise solution in ocean zoning disputes. Here we synthesize all empirical studies comparing biological measures (biomass, density, species richness, and size of organisms) in no-take marine reserves and adjacent partially protected and unprotected areas across a range of geographic locations worldwide. We demonstrate that while partially protected areas may confer some benefits over open access areas, no-take reserves generally show greater benefits and yield significantly higher densities of organisms within their boundaries relative to partially protected sites nearby.
\end{abstract}

KEY WORDS: Marine reserves $\cdot$ Marine protected areas $\cdot$ Protection level $\cdot$ Conservation $\cdot$ Ocean zoning

\section{INTRODUCTION}

Human activities have broad effects on coastal and oceanic marine systems (Halpern et al. 2008b), often degrading ecosystem services (UNEP 2006), including many fisheries worldwide (Gewin 2004, Worm et al. 2006). These changes have led to calls for more ecosystem-based approaches to marine management, including ocean zoning and the implementation of marine protected areas (Palumbi 2002, Lubchenco et al. 2003, Browman \& Stergiou 2004, Crowder et al. 2006, Halpern et al. 2008a). In particular, ocean zoning provides a means to spatially separate incompatible human activities and reduce conflict among user groups (Crowder et al. 2006). However, when attempt- ing to implement a zoning approach or establish a network of MPAs, it is critical to understand the potential ecological consequences of different types of restrictions. There is often a tension between conservationists and extractive user groups regarding the level of protection established, and it is important to evaluate whether this friction is necessary.

No-take marine reserves are often promoted for their ability to offer simple and full protection for marine resources and ecosystems. Numerous syntheses of monitoring studies have documented beneficial effects of reserve protection (Palumbi 2002, Halpern 2003, S. E. Lester unpubl. data), particularly for biomass and density of exploited species within reserve boundaries (Gell \& Roberts 2003, Micheli et al. 2004). In addition to 
these demonstrated conservation benefits, there is some theoretical work and more limited empirical evidence that reserves can produce fisheries benefits, either through export of larvae or spillover of adults into unprotected waters (Roberts et al. 2001, Halpern et al. 2004, Hilborn et al. 2004, Goni et al. 2006). Marine reserves are also promoted over partially protected areas for political reasons, such as less complicated regulations and more straightforward enforcement (Bohnsack 2004).

Despite the benefits of marine reserves, prohibiting all extractive activities in certain areas can have socioeconomic costs. Marine reserves often face strong opposition by extractive users, making the process of reserve implementation politically difficult and polarizing. Indeed, even if reserves benefit fisheries, local fishers may be negatively affected by the loss of fishing grounds, at least in the short-term. As a result, MPAs with less restrictive regulations are typically seen as a politically more feasible management strategy and are often advanced as compromise solutions (NRC 2001, Shears et al. 2006). For example, MPAs often allow recreational fishing, subsistence fishing, or fishing with less destructive gear types, depending on the stated management goals.

Partially protected areas have also been shown to produce ecological responses (e.g. Murawski et al. 2000, Blyth-Skyrme et al. 2006, Floeter et al. 2006), although it is difficult to generalize about these effects because empirical results remain scattered throughout the literature. A further challenge is that the intensity and frequency of permitted extractive or destructive activities is a source of variation that is difficult to quantify and thus control for in analyses. We address these challenges here by synthesizing available peerreviewed data on MPA performance in those locations where there is an adjacent marine reserve. In doing so, we exclude those studies that have looked only at MPA performance, but we gain power by having a controlled, direct comparison to no-take marine reserves. These results can inform decisions on appropriate or necessary level of protection when establishing MPAs in order to meet specified management or conservation goals.

\section{METHODS}

We conducted a comprehensive survey of peerreviewed scientific literature to compile a database of studies documenting and comparing biological effects of fully-protected no-take marine reserves, partially protected marine protected areas (MPAs) and open access areas, all within the same vicinity. Studies must have measured at least 1 of 4 key biological variables (density, biomass/area of organisms, individual organism size, or species richness/area) and must have quantified the variable(s) either (1) inside the reserve, inside the partial protection area and outside the protected areas (open access) after protection was implemented, or (2) in all three areas before and after protection was implemented. The areas referred to in this paper as 'open access' may be subject to some fishing restrictions (e.g. no dynamite fishing), but are less protected than the no-take reserves and partial protection areas. Furthermore, in many of the studies, recreational or subsistence fishing is allowed in the 'partial protection' area (Table 1), while recreational, subsistence and some commercial fishing are allowed in the 'open access' area.

The resulting database contains 20 peer-reviewed scientific publications published between 1977 and 2007 examining 21 protected areas in 11 countries (Table 1). For each study, we extracted quantitative data from text, tables, and figures for the 4 biological variables. Data were extracted at the most aggregated taxonomic level available, even if the level of taxonomic resolution differed within or among studies. If a study reported data for categories of other variables (e.g., by depth, habitat type, or organism size classes), we calculated an un-weighted average of the values reported for these categories to extract a single value for each protection level. If data were collected over time, we used the most recent because they represent the longest duration of protection (for before/after comparisons, this holds for the after data).

To quantify the effects of different levels of protection using comparable metrics across studies, we calculated response ratios for the biological variables as (1) the ratio of inside the no-take reserve to the open access area, (2) the ratio of the partially protected area to the open access area, and (3) the ratio of the no-take reserve to the partially protected area. If the study included before and after protection data, the above three ratios were calculated using the ratios of after versus before for each of the protection levels.

When data were extracted for multiple taxa in a given study, we averaged these response ratios to determine the overall study ratio for all taxa examined, such that study-level ratios can represent from 1 to $>100$ species depending on the study (Table 1). Two studies (McClanahan \& Muthiga 1988, McClanahan et al. 2006) reported data separately for more than 1 of the 3 broad taxonomic groups (fish, invertebrates, algae), and thus we calculated an average for each group first and then averaged these group values to determine the overall ratio. For all analyses, we used log ratios to meet statistical criteria (Hedges et al. 1999) and conducted all statistical tests using JMP 7.0 (SAS Institute). 


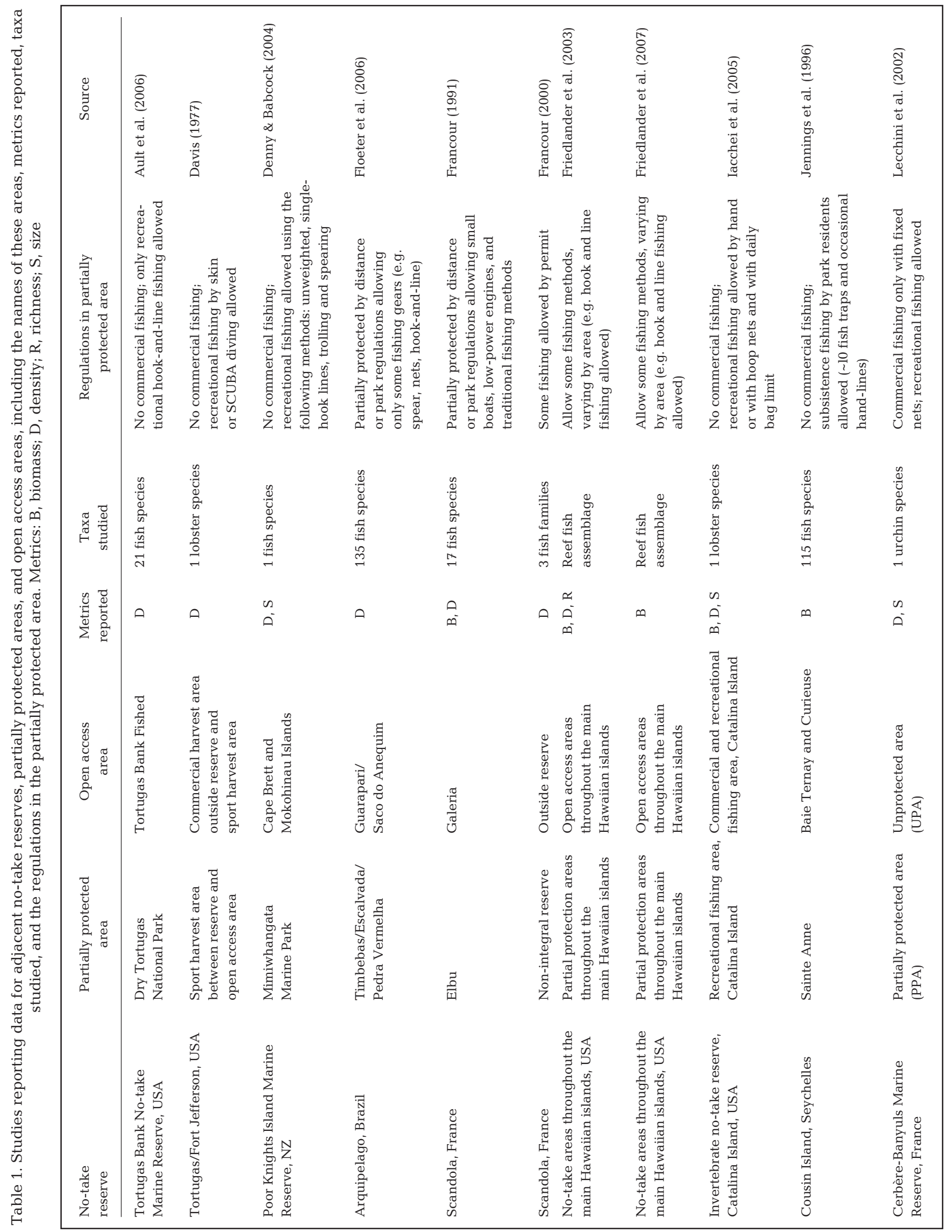




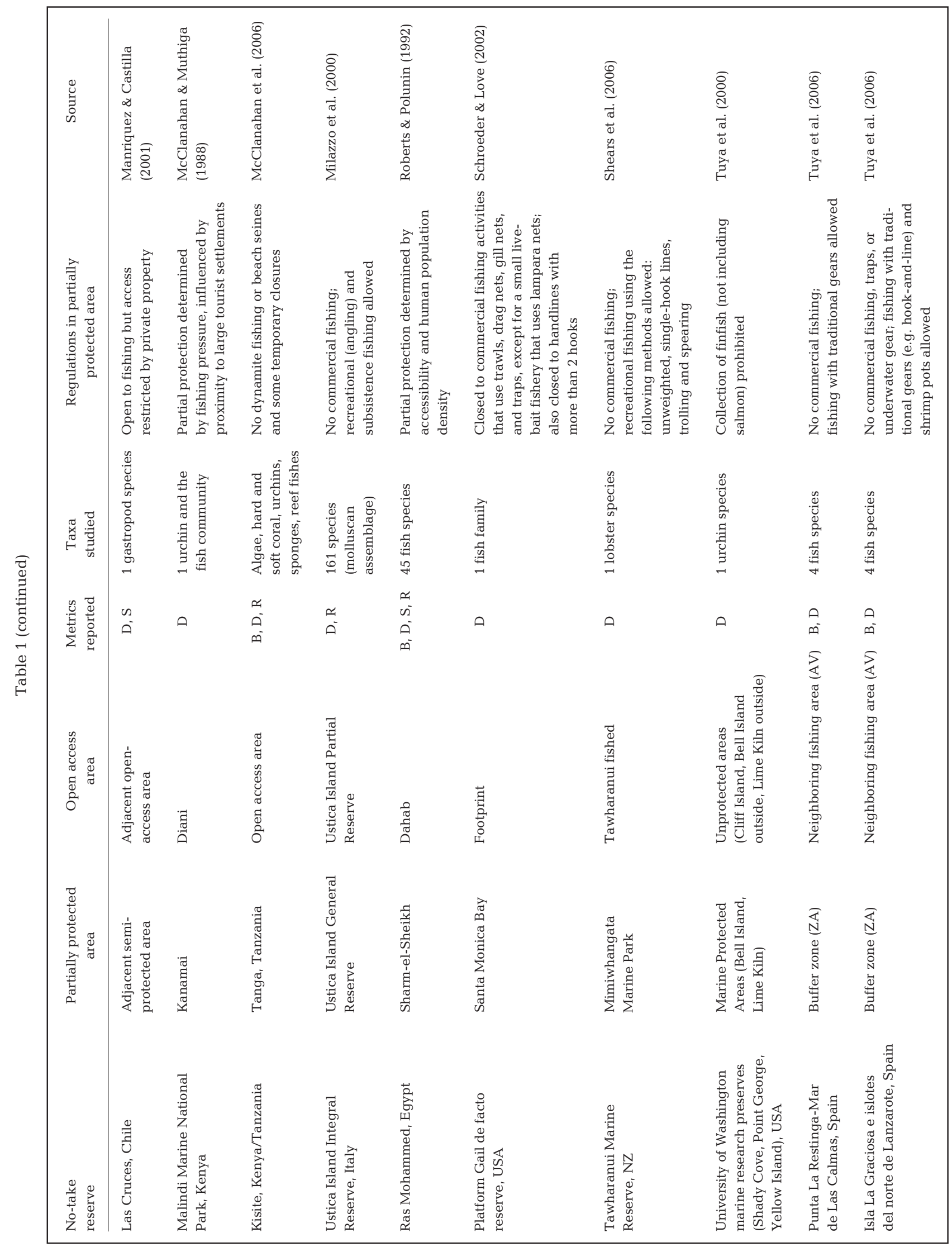




\section{RESULTS}

Partially protected areas (MPAs) may confer some ecological benefits relative to unprotected areas, producing positive but non-significant responses for biomass, density, richness and individual size relative to unprotected areas (Fig. 1) (Partial:open response ratios; $t$-tests, means not significantly different from zero: $p>0.1$ for all metrics). No-take reserves had larger increases on average relative to unprotected areas than those for partially protected areas (Fig. 1: No-take:open response ratios); these responses were statistically significant for density ( $t$-test, means significantly different from zero: $p=0.015$ ) and suggestive (though non-significant) for organism size ( $\mathrm{p}=$ 0.09), but not significant for biomass or species richness ( $p>0.1$ ). Additionally, the reserve effects documented in this dataset are comparable to values in previous more comprehensive analyses of no-take reserves (Halpern 2003; Fig. 1: Halpern ratios).

To control for potential differences among study locations and species sampled, we conducted pairwise comparisons of full versus partial protection areas. We found that no-take areas had higher biomass, density, species richness and individual organism size on average relative to partially protected areas (Fig. 2). This difference was statistically significant only for density ( $p=0.02$ for density, $0.1<p<0.9$ for biomass, species richness and organism size), although it should be noted that organism size and species richness had very low sample sizes $(\mathrm{n}=5, \mathrm{n}=4$, respectively).

\section{DISCUSSION}

While partially protected areas may result in higher values of ecological metrics than open access areas, no-take reserves generally produced greater increases and yielded significantly higher densities of organisms within their boundaries relative to partially protected sites nearby. These results suggest that no-take reserves have advantages over less protected areas and may therefore represent a preferable management strategy, depending on management goals and social, economic and political constraints. Although the effect of no-take protection relative to partial protection was only significant for density, this is also the biological measure for which we had the most data. The no-take:open ratios from our synthesis are within the same range as those of Halpern's (2003) more comprehensive analysis of no-take reserves, and there is a remarkable similarity between studies for density, organism size and species richness. This suggests that the reserves in our dataset are a representative sub-

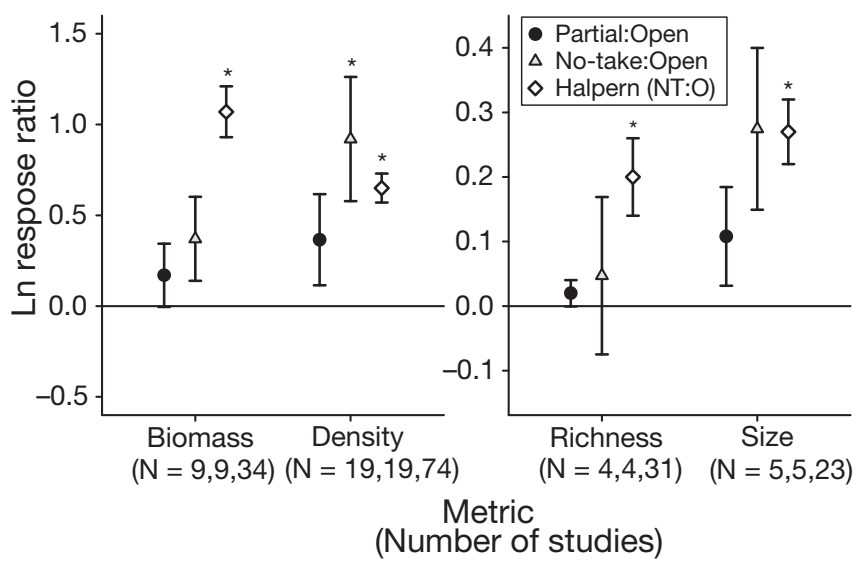

Fig. 1. Response ratios of overall study means $( \pm \mathrm{SE})$ for partially protected areas compared to open access areas $(\bullet)$, for no-take reserves compared to open access areas from this synthesis $(\Delta)$, and for no-take reserves compared to open access areas from the comprehensive synthesis of Halpern $(2003)(\diamond) .{ }^{*}$ : mean significantly different from zero $(t$-test, $p<$ 0.05). Sample size for each ratio is shown in parentheses following the sequence in the plot. Response ratios (RR) from Halpern (2003) were converted from logRR to lnRR to match the transformation used in this synthesis

sample and we should be able to detect an effect of partial protection, at least for density, if such an effect exists.

It is important to note that there is considerable variability in the documented effects of no-take versus partial protection, likely resulting from various factors that could not be accounted for in our analyses due to lack of information or insufficient data, including duration of protection, MPA/reserve size, habitat type and qual-

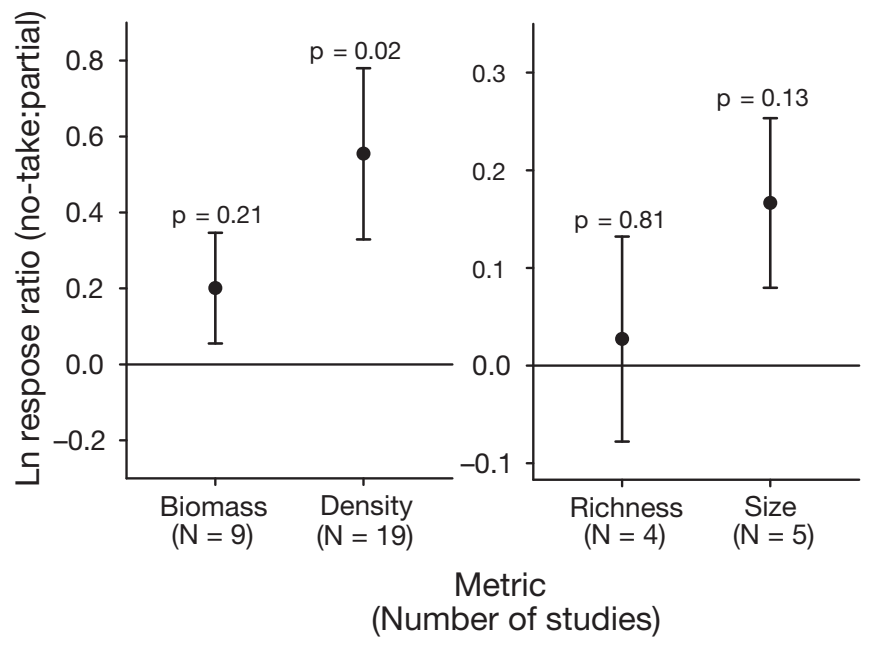

Fig. 2. Response ratios of overall study means $( \pm \mathrm{SE})$ for notake reserves and partially protected areas. p-values indicate the results of $t$-tests (testing for means significantly different from zero) 
ity, and enforcement and compliance. Additionally, given the limited amount of data available, we aggregated across all taxa and thus were not able to control for specific taxon traits, such as trophic level or whether or not taxa are exploited. Thus, there is a critical need for more empirical studies documenting biological effects in adjacent open access, partially protected, and no-take areas; these studies should be conducted in a variety of locations and habitat types worldwide and focus on a range of taxa. Ideally such studies would also collect data prior to protection to avoid confounding effects of protection when MPAs are sited in 'better' areas.

We did not find significant ecological effects of partially protected areas relative to open access areas. A more complete synthesis of the studies that have examined only effects of partially protected MPAs relative to open access areas could help refine our understanding of the potential for MPAs to provide management and conservation benefits; a key challenge would be accounting for and controlling likely drivers of differences in MPA performance (e.g. the range and intensity of activities permitted within the MPA as well as differences in habitat, geography and species composition). Almost certainly, the amount of protection provided to species of interest within MPAs (e.g. fishery species) will greatly influence MPA performance relative to no-take marine reserves. Indeed, it is not surprising that we failed to document significant ecological effects of partially protected MPAs given that most of the studies we reviewed reported results for species targeted (although often by different fishing methods) in both open access and partially protected areas. Some species, particularly those heavily targeted by both commercial and recreational fishers, may be protected only by no-take reserves. Our focus here on studies that examined both MPAs and no-take reserves does not eliminate these challenges, but allowed us to directly compare these management options and helped minimize the potential for factors such as habitat type, species composition, or geography to influence the results.

Many partially protected areas, including those in this study, frequently exclude commercial fishing but allow recreational and/or subsistence fishing (Table 1). There is a widely held perception that recreational fishing does not have a substantial impact on marine ecosystems. For example, a recent poll prepared for the American Sportfishing Association reported that $64 \%$ of Californians think that recreational fishing is a 'not serious' threat to marine ecosystems (FRC 2007). However, there is a growing body of evidence indicating that recreational fishing can constitute a significant portion of the regional catch for some species (Schroeder \& Love 2002, Coleman et al. 2004, Cooke \&
Cowx 2004), and the lack of an MPA effect in our analyses on species that remain targeted by recreational fisheries further supports this evidence. Schroeder \& Love (2002) examined $20 \mathrm{yr}$ of landings data for nearshore fisheries species in California and found that for 16 of 17 species, recreational angling was the primary source of fishing mortality. Even catch-and-release fisheries can have dramatic effects on longer-lived species due to relatively small increases in mortality incurred post-hooking (Schroeder \& Love 2002). Additionally, recreational fishing can have ecosystem-level effects similar to those from commercial fishing (Cooke \& Cowx 2004, 2006); in some cases, recreational fishing can have even larger impacts because of a greater focus on higher trophic levels (Coleman et al. 2004) and shallower nearshore environments (Cooke \& Cowx 2004).

One potential reason for smaller ecological effects in MPAs is that in some cases fishing effort becomes concentrated in partially protected areas relative to open access areas because of a perception among fishers that MPAs are likely to have more or larger fish due to the exclusion of commercial fishing (Denny \& Babcock 2004, Shears et al. 2006). Likewise, rotational closures also often experience high levels of fishing that counteract the benefits of temporary protection (Murawski et al. 2005). For example, a study investigating rotational management in Hawaii found that fish biomass increased during closed periods, but not enough to compensate for the reduction in biomass during open periods (Williams et al. 2006).

MPA and reserve designation requires a balance of ecological, political, economic and social goals. Thus, regardless of the larger ecological responses in notake reserves relative to partially protected areas, human needs will require MPA networks to allow a mix of protection levels and restrictions to accommodate multiple objectives, human activities and stakeholder groups. Additionally, partial protection can be used to exclude activities that are deemed too destructive (such as benthic trawl commercial fishing) despite potentially increasing fishing pressure for some species. It is important, however, for policy makers and managers to be aware of the ecological cost of conferring lower levels of protection in MPAs so that management decisions can be fairly evaluated by their ability to meet stated goals. Furthermore, there are numerous other advantages of no-take protection over partial protection not tested here (Schroeder \& Love 2002, Bohnsack 2004). For example, reserves may provide control areas for fisheries-independent stock assessments and for teasing apart natural versus anthropogenic changes to marine ecosystems. Additionally, reserves can enhance various non-extractive uses such as recreation and tourism, many of which 
can provide economic benefits (Bhat 2003, Brander et al. 2007). Determining the appropriate level of protection for different areas of the ocean requires a careful balancing of conservation and management priorities, and analyses like those presented here can help inform this decision-making process.

Acknowlegements. This work was supported by the Partnership for Interdisciplinary Studies of Coastal Oceans (PISCO) funded by the David and Lucile Packard Foundation and the Gordon and Betty Moore Foundation (Contribution number 311) (S.E.L.) and a grant from the Packard Foundation to the National Center for Ecological Analysis and Synthesis to evaluate the science of ecosystem-based management in coastal marine ecosystems (B.S.H.). We appreciate comments from A. Abeles and three anonymous reviewers on earlier versions of the manuscript.

\section{LITERATURE CITED}

Ault JS, Smith SG, Bohnsack JA, Luo JG, Harper DE, McClellan DB (2006) Building sustainable fisheries in Florida's coral reef ecosystem: positive signs in the Dry Tortugas. Bull Mar Sci 78:633-654

Bhat MG (2003) Application of non-market valuation to the Florida Keys marine reserve management. J Environ Manag 67:315-325

Blyth-Skyrme RE, Kaiser MJ, Hiddink JG, Edwards-Jones G, Hart PJB (2006) Conservation benefits of temperate marine protected areas: variation among fish species. Conserv Biol 20:811-820

Bohnsack JA (2004) Why have no-take marine protected areas? Am Fish Soc Symp 42:183-193

Brander LM, Van Beukering P, Cesar HSJ (2007) The recreational value of coral reefs: a meta-analysis. Ecol Econ 63:209-218

Browman HI, Stergiou KI (2004) Marine protected areas as a central element of ecosystem-based management: defining their location, size and number. Mar Ecol Prog Ser 274:271-272

> Coleman FC, Figueira WF, Ueland JS, Crowder LB (2004) The impact of United States recreational fisheries on marine fish populations. Science 305:1958-1960

Cooke SJ, Cowx IG (2004) The role of recreational fishing in global fish crises. BioScience 54:857-859

Cooke SJ, Cowx IG (2006) Contrasting recreational and commercial fishing: searching for common issues to promote unified conservation of fisheries resources and aquatic environments. Biol Conserv 128:93-108

> Crowder LB, Osherenko G, Young OR, Airame S and others (2006) Resolving mismatches in US ocean governance. Science 313:617-618

Davis GE (1977) Effects of recreational harvest on a spiny lobster, Panulirus argus, population. Bull Mar Sci 27: 223-236

> Denny CM, Babcock RC (2004) Do partial marine reserves protect reef fish assemblages? Biol Conserv 116:119-129

Floeter S, Halpern BS, Ferreira C (2006) Effects of fishing and protection on Brazilian reef fishes. Biol Conserv 128: 391-402

Francour P (1991) The effect of protection level on a coastal fish community at Scandola, Corsica. Rev Ecol (Terre Vie) 46:65-81

Francour P (2000) Long term monitoring of Posidonia ocean- ica fish assemblages of the Scandola Marine Reserve (Corsica, northwestern Mediterranean). Cybium 24:85-95

FRC (Field Research Corporation) (2007) A survey of California adults and anglers about threats to marine life, fish populations and the state's Marine Life Protection Act. Field Research Corporation, San Francisco, CA. Available at: www. keepamericafishing.org/images/ASA_FieldSurvey.pdf

Friedlander AM, Brown EK, Jokiel PL, Smith WR, Rodgers KS (2003) Effects of habitat, wave exposure, and marine protected area status on coral reef fish assemblages in the Hawaiian archipelago. Coral Reefs 22:291-305

Friedlander AM, Brown EK, Monaco ME (2007) Coupling ecology and GIS to evaluate efficacy of marine protected areas in Hawaii. Ecol Appl 17:715-730

Gell FR, Roberts CM (2003) Benefits beyond boundaries: the fishery effects of marine reserves. Trends Ecol Evol 18: $448-455$

> Gewin V (2004) Troubled waters: the future of global fisheries. PLoS Biol 2(4):e113

> Goñi R, Quetglas A, Reñones O (2006) Spillover of spiny lobsters Palinurus elephas from a marine reserve to an adjoining fishery. Mar Ecol Prog Ser 308:207-219

> Halpern BS (2003) The impact of marine reserves: do reserves work and does reserve size matter? Ecol Appl 13: S117-S137

Halpern BS, Gaines SD, Warner RR (2004) Confounding effects of the export of production and the displacement of fishing effort from marine reserves. Ecol Appl 14: 1248-1256

> Halpern BS, McLeod KL, Rosenberg AA, Crowder LB (2008a) Managing for cumulative impacts in ecosystem-based management through ocean zoning. Ocean Coast Manag 51:203-211

> Halpern BS, Walbridge S, Selkoe KA, Kappel CV and others (2008b) A global map of human impact on marine ecosystems. Science 319:948-952

Hedges LV, Gurevitch J, Curtis PS (1999) The meta-analysis of response ratios in experimental ecology. Ecology 80: 1150-1156

Hilborn R, Stokes K, Maguire JJ, Smith T and others (2004) When can marine reserves improve fisheries management? Ocean Coast Manag 47:197-205

Iacchei M, Robinson P, Miller KA (2005) Direct impacts of commercial and recreational fishing on spiny lobster, Panulirus interruptus, populations at Santa Catalina Island, California, United States. N Z J Mar Freshw Res 39: 1201-1214

Jennings S, Marshall SS, Polunin NVC (1996) Seychelles' marine protected areas: comparative structure and status of reef fish communities. Biol Conserv 75:201-209

Lecchini D, Lenfant P, Planes S (2002) Variation in abundance and population dynamics of the sea urchin Paracentrotus lividus on the Catalan coast (north-western Mediterranean Sea) in relation to habitat and marine reserve. Vie Milieu 52:111-118

Lubchenco J, Palumbi SR, Gaines SD, Andelman S (2003) Plugging a hole in the ocean: the emerging science of marine reserves. Ecol Appl 13:S3-S7

Manriquez PH, Castilla JC (2001) Significance of marine protected areas in central Chile as seeding grounds for the gastropod Concholepas concholepas. Mar Ecol Prog Ser 215:201-211

> McClanahan TR, Muthiga NA (1988) Changes in Kenyan coral reef community structure and function due to exploitation. Hydrobiologia 166:269-276

> McClanahan TR, Verheij E, Maina J (2006) Comparing the management effectiveness of a marine park and a mul- 
tiple-use collaborative fisheries management area in East Africa. Aquat Conserv Mar Freshw Ecosyst 16:147-165

Micheli F, Halpern BS, Botsford LW, Warner RR (2004) Trajectories and correlates of community change in no-take marine reserves. Ecol Appl 14:1709-1723

Milazzo M, Chemello R, Badalamenti F, Riggio S (2000) Molluscan assemblages associated with photophilic algae in the marine reserve of Ustica Island (Lower Tyrrhenian Sea, Italy). Ital J Zool (Modena) 67:287-295

Murawski SA, Brown R, Lai HL, Rago PJ, Hendrickson L (2000) Large-scale closed areas as a fishery-management tool in temperate marine systems: the Georges Bank experience. Bull Mar Sci 66:775-798

Murawski SA, Wigley SE, Fogarty MJ, Rago PJ, Mountain DG (2005) Effort distribution and catch patterns adjacent to temperate MPAs. ICES J Mar Sci 62:1150-1167

NRC (National Research Council) (2001) Marine protected areas: tools for sustaining ocean ecosystems. National Academies Press, Washington, DC

Palumbi SR (2002) Marine reserves: a tool for ecosystem management and conservation. Pew Oceans Commission, Arlington, VA

Roberts CM, Polunin N (1992) Effects of marine reserve protection on northern Red Sea fish populations. Proc 7th Int Coral Reef Symp 2:969-977

Roberts CM, Bohnsack JA, Gell F, Hawkins JP, Goodridge R

Editorial responsibility: Romuald Lipcius,

Gloucester Point, Virginia, USA
(2001) Effects of marine reserves on adjacent fisheries. Science 294:1920-1923

Schroeder DM, Love MS (2002) Recreational fishing and marine fish populations in California. Calif Coop Ocean Fish Invest Rep 43:182-190

Shears NT, Grace RV, Usmar NR, Kerr V, Babcock RC (2006) Long-term trends in lobster populations in a partially protected vs. no-take marine park. Biol Conserv 132:222-231

Tuya FC, Soboil ML, Kido J (2000) An assessment of the effectiveness of marine protected areas in the San Juan Islands, Washington, USA. ICES J Mar Sci 57:1218-1226

Tuya F, Garcia-Diez C, Espino F, Haroun RJ (2006) Assessment of the effectiveness of two marine reserves in the Canary Islands (eastern Atlantic). Cienc Mar 32:505-522

UNEP (United Nations Environment Programme) (2006) Marine and coastal ecosystems and human well-being: a synthesis report based on the findings of the Millennium Ecosystem Assessment. United Nations Environment Programme, Nairobi

Williams ID, Walsh WJ, Miyasaka A, Friedlander AM (2006) Effects of rotational closure on coral reef fishes in WaikikiDiamond Head Fishery Management Area, Oahu, Hawaii. Mar Ecol Prog Ser 310:139-149

Worm B, Barbier EB, Beaumont N, Duffy JE and others (2006) Impacts of biodiversity loss on ocean ecosystem services. Science 314:787-790

Submitted: December 17, 2007; Accepted: June 5, 2008 Proofs received from author(s): August 28, 2008 